\title{
Evaluation of the Performance of SWAT Model to Simulate Stream Flow of Mojo River Watershed: In the Upper Awash River Basin, in Ethiopia
}

\author{
Ahmednasir Amin*, Nade Nuru \\ Institute of Technology, Oda Bultum University, Chiro, Ethiopia \\ Email address: \\ aamadnasiramin@gmail.com (A. Amin) \\ ${ }^{*}$ Corresponding author
}

To cite this article:

Ahmednasir Amin, Nade Nuru. Evaluation of the Performance of SWAT Model to Simulate Stream Flow of Mojo River Watershed: In the Upper Awash River Basin, in Ethiopia. Hydrology. Vol. 8, No. 1, 2020, pp. 7-18. doi: 10.11648/j.hyd.20200801.12

Received: June 8, 2020; Accepted: June 28, 2020; Published: August 10, 2020

\begin{abstract}
The assessment of the accessibility of water in the basin and significance setting of its use is essential before planning for the expansion and development of additional sectors which poses pressure on water availability. The main purpose of this study was to evaluate the performance of SWAT model to simulate stream flow of Mojo River. The performance evaluation of the model was to obtain the water balances was conducted. In this study both secondary and primary data were used. The SWAT model was used for data analysis. In this study for stream flow yield simulation the parameters involving surface runoff (CN2.mgt) and ground water (ALPHA_BNK.rte was found to be the most sensitive parameters. A good agreement between observed and simulated discharge were observed, which was verified using both graphical technique and quantitative statistics. The value of $\mathrm{R}^{2}=0.80, \mathrm{NSE}=0.75, \mathrm{RSR}=0.5$ and $\mathrm{PBIAS}=-10.6$ obtained during calibration and $\mathrm{R}^{2}$ value 0.76 , NSE value 0.69 , RSR value 0.56 and PBIAS -14.4 obtained during validation as well as the uniformly scatter points along the 1:1 line during calibration and validation justify that the model is very good in simulating observed steam flow. From the results the total annual surface water available yields is estimated around 0.401Billion Cubic Meters (BCM).
\end{abstract}

Keywords: Simulate Streamflow, Performance of SWAT Model, Mojo River Watershed

\section{Introduction}

\subsection{Background}

The adequacies of the water for irrigation need supply for specific area is seldom known for a particular year. Likewise; the determination of net consumptive use, records are inadequate for estimating rates for individual years but are believed to be reliable when taken as an average over a period of years. Consumptive use will be greater during dry, hot summers, and a greater part of the water must be supplied by irrigation during these years [5]. The industries in the major cities of Ethiopia located in the basin are the sources of water pollution. Urbanization, industrial development of agricultural chemicals and fertilizers overcharged the carrying capacity of water bodies and resulted in deterioration of surface water quality and groundwater aquifer in the basin. This issue requires an urgent attention from the government and stakeholders. Water logging and salinization are putting increasing pressure on land and water quality in the basin in irrigated agriculture. Through collection and analysis of reliable and adequate data on water resource status, sound decisions can be made on how best to develop and manage these resources. Proper assessment of the water resources in time and space is important to plan future water use rationally and on a sustainable basis. The assessment of the availability of water in the basin and priority setting of its use is important before planning for the expansion and development of additional sectors which poses pressure on water availability [5]. The main purpose was to evaluate the performance of SWAT model to simulate stream flow of Mojo River.

\subsection{Statement of the Problem}

Ethiopia is blessed with ample water resources. The 
country has 12 river basins with an annual runoff volume of 122 billion $\mathrm{m}^{3}$ of water and an estimated 2.6 to 6.5 billion $\mathrm{m}^{3}$ of ground water potential, which makes an average of 1575 $\mathrm{m}^{3}$ of physically available water per person per year, a relatively large volume [10]. However, distribution and availability of water is erratic both in space and time. Hence, despite the abundance, the country is highly water-scarce [17]. Of the total water resources available to Ethiopia, only $9 \%$ remains in the country; the bulk flows downstream to neighboring countries, and is particularly important for Somalia, Kenya, Sudan and Egypt [21, 17].

Awash River originates in the Central Highlands and flows down northeast for a length of $1200 \mathrm{~km}$ has longer flooding period and larger dry seasons at downstream. However, due to under development of this natural resource most people are influenced by these extreme events. Mojo River is one of the rivers that face competition among users. The competition for water among the major users of the river is increasing due to socio-economic development and population growth in the catchment. Equitable access and sustainable water resources development in a participatory approach of all stakeholders is important to cope with water scarcity. Therefore, the aim of this research was to investigate the availability of surface water of Mojo River with SWAT model.

\section{Materials and Methods}

\subsection{Description of Study Area}

This study was conducted at Modjo River, which is located in the upper part of Awash River basin, Ethiopia. Mojo watershed having a total area of $2017.09 \mathrm{~km}^{2}$ is situated in central Oromia Regional state, Ethiopia, Figure 1 Geographically it is located between latitudes of $8^{\circ} 16^{\prime} \mathrm{N}$ and $9^{\circ} 18^{\prime} \mathrm{N}$ and longitude of $37^{\circ} 57^{\prime} \mathrm{E}$ and $39^{\circ} 17^{\prime} \mathrm{E}$. The Modjo watershed drains finally into Awash River. The mean annual rainfall of the area ranges from 918.50 to $1226 \mathrm{~mm}$ with more than $83 \%$ of annual rainfall falling during June to September. The mean maximum temperature of the watershed is ranging from $21^{\circ} \mathrm{C}$ to $27^{\circ} \mathrm{C}$ the highest being recorded in the month of May and the lowest in July. The mean minimum temperature ranges from $8^{\circ} \mathrm{C}$ to $12^{\circ} \mathrm{C}$ where the minimum and maximum are occurring in the month of December and April respectively. The altitude of the watershed ranges from $1592.15 \mathrm{msl}$ at the river bed to $3065.49 \mathrm{msl}$ at the upper part of the watershed.

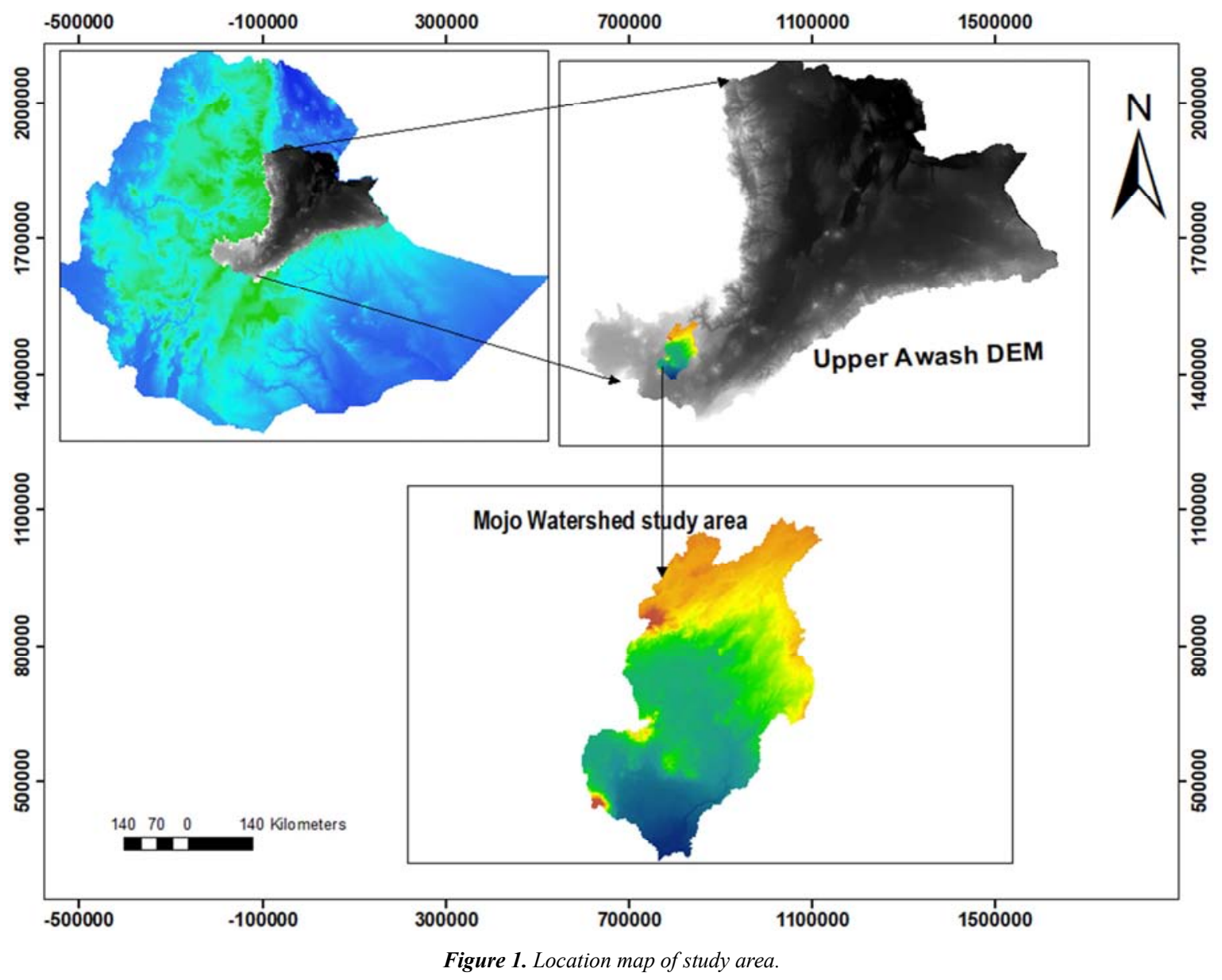

\subsubsection{Rainfall Data}

Effective rainfall was calculated based on 31 years monthly rainfall data collected from four stations. The annual rainfall in the catchment or mojo watershed during (1987-2017) ranges $918-1226 \mathrm{~mm}$. 


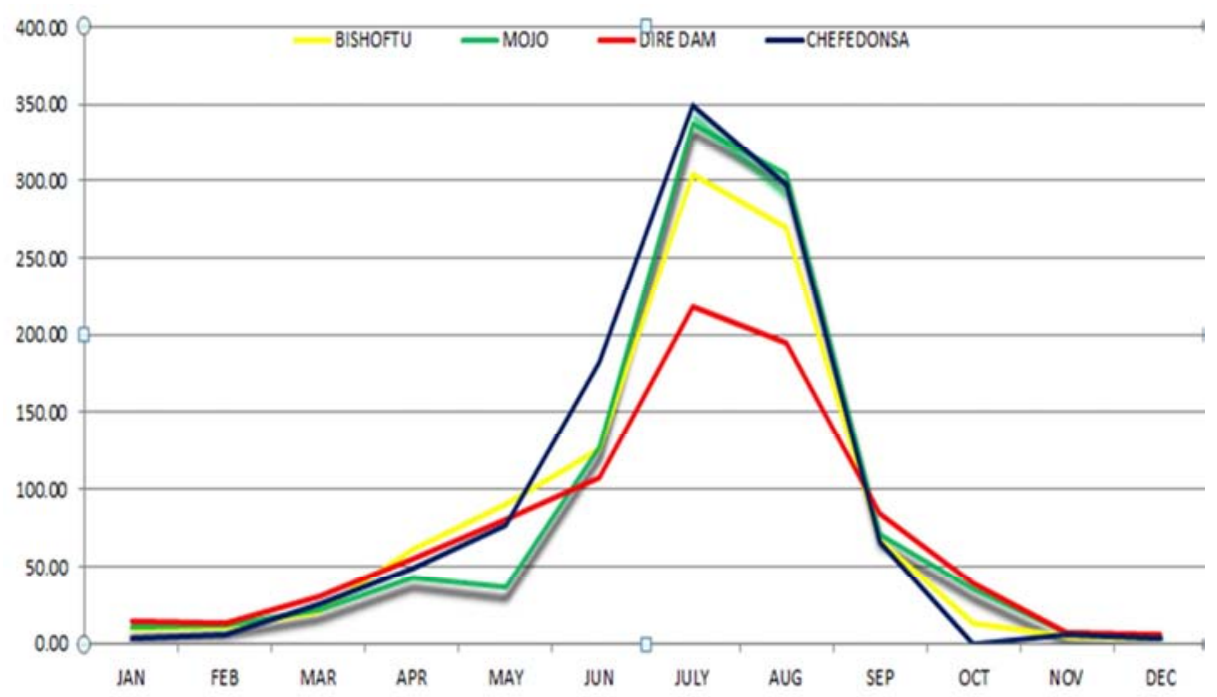

Figure 2. Rainfall pattern of Mojo Watershed.

\subsubsection{Land Use Land Cover}

The land use is one of the main factors affecting surface runoff and evapotranspiration in the watershed area. The major land use and land cover types of the catchment are irrigated agricultural land, plantation forest, pastureland, degraded (barren) land, settlement (rural and urban), and water bodies. According to SWAT land use and land cover classification, Agriculture (Cultivation) is the dominant land use in the study area (figure 3). Around $63.7 \%$ of the watershed area is covered by agricultural land (cultivated land).

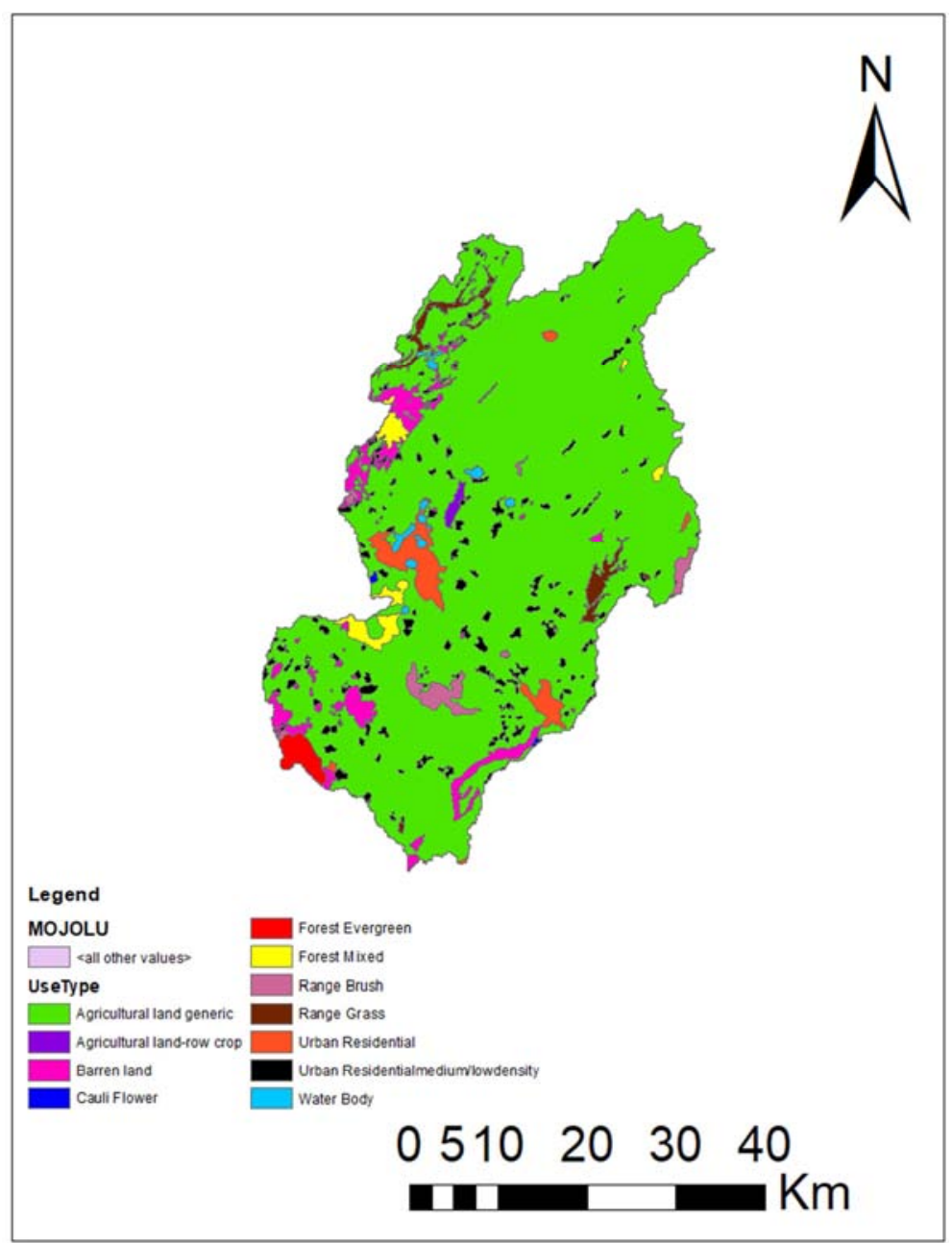

Figure 3. Land use Land cover of Mojo watershed. 


\subsubsection{Soil Types}

According to the FAO/UNESCO soil classification system, the mojo watershed area comprises five major soil types.

Table 1. Major soil of Mojo watershed and the area distribution.

\begin{tabular}{llllll}
\hline Nos. & Identified soil types & Major soils & Textures & Area (Ha) & Area (\%) \\
\hline 1 & Vitric andosols & Andosols & Loam & 121261.68 & 60.11 \\
2 & Pellic Vertisols & Vertisols & Clay & 2569.53 & 1.25 \\
3 & Chromic Luvisols & Luvisols & Clay loam & 59966.77 & 29.73 \\
4 & Umric Leptosols & Leptosols & Loam & 2612.73 & 1.30 \\
5 & Chromic Cambisols & Cambisols & Sand Clay Loam & 15301.69 & 7.57 \\
\hline
\end{tabular}

\subsection{Data Collection}

\subsubsection{Secondary Data}

All daily observed meteorological dataset such as rainfall, maximum and minimum temperature, relative humidity, wind speed, and sunshine hour of four representative stations within and around watersheds (Mojo, Bishoftu, Diredam and Chefedonsa) for a period of 31years (1987-2017) were collects from National Meteorology Agency (NMA). For Hydrological modelling of Mojo watershed, stream flow datasets of Mojo River station recorded from (1987-2016), Spatial data (topographic, land use/cover data and map, soil map) and digital elevation model (DEM) data with a resolution of 30x30 was collected from Ethiopian Ministry of water, Irrigation and Energy (MOWIE).

\subsubsection{Estimating the Missing Data}

While working with hydrological model, it is common to encounter missing weather data values from observed records for so many reasons. It is very essential to fill in the missing data when a hydrological basin analysis needs a continuous data. Also in availability of stream flow studies it is common to check the gaps in the time series of precipitation and temperature before filling the missing data. Simple mathematical equation was applied to quantify the total percentage of the missing value from the total data series as follows.

$$
\% \text { of missed data } a=\left[\frac{X_{1}}{X_{2}}\right] * 100
$$

Where, $\mathrm{X}_{1}$ is count of missed data; $\mathrm{X}_{2}$ is whole data set

The filling of missing data is very essential to perform metrological data analysis and stream flow simulation using data of long time series. In this study two methods were applied to fill the missing values; Arithmetic mean method (for the normal annual precipitations at surrounding gauges are within the range of $10 \%$ of the normal annual precipitation of station with missed data)

$$
\mathrm{P}_{\mathrm{X}}=\frac{1}{\mathrm{n}}\left(\mathrm{P}_{1}+\mathrm{P}_{2}+\cdots+\mathrm{P}_{\mathrm{n}}\right)
$$

Where, $\mathrm{P}_{1}, \mathrm{P}_{2} \ldots \mathrm{P}_{\mathrm{n}}$ are the precipitation of index stations

$P_{X}$ is that of the missing station and $n$, is the number of index stations.

And the normal ratio (for the surrounding gauges have the normal annual precipitation exceeding $10 \%$ of the gauge with missed data) for rainfall.

$$
P_{X}=\frac{N_{X}}{n}\left[\frac{P_{1}}{N_{1}}+\frac{P_{2}}{N_{2}}+\cdots+\frac{P_{n}}{N_{n}}\right]
$$

Where, $\mathrm{P}_{1}, \mathrm{P}_{2} \ldots \mathrm{P}_{\mathrm{n}}$ are the rainfall data of index stations, $\mathrm{N}_{1}$, $\mathrm{N}_{2}, \ldots \mathrm{N}_{\mathrm{n}}$ the normal annual rainfall of index stations and $P_{X}$, $\mathrm{N}_{\mathrm{X}}$ the values for the missing station " $\mathrm{X}$ " in question and $\mathrm{n}$, is the number of stations surrounding station " $\mathrm{X}$ ".

\subsubsection{Data Consistency Test}

Double mass curve method was used to check the consistency of the data (Figure 6) by comparing data of a single station with that of a pattern composed of the data from other station. The data of the annual rainfall of the doubtful station and the average rainfall of the group of base stations covering a long period was arranged in the reverse chronological order. The cumulative values of the doubtful stations were plotted against the cumulative average groups. From Figure 6 the annual cumulative rainfall $(\mathrm{mm})$ for each stations were put in " $y$ - axis and the average annual cumulative $(\mathrm{mm})$ in " $\mathrm{x}$-axis.

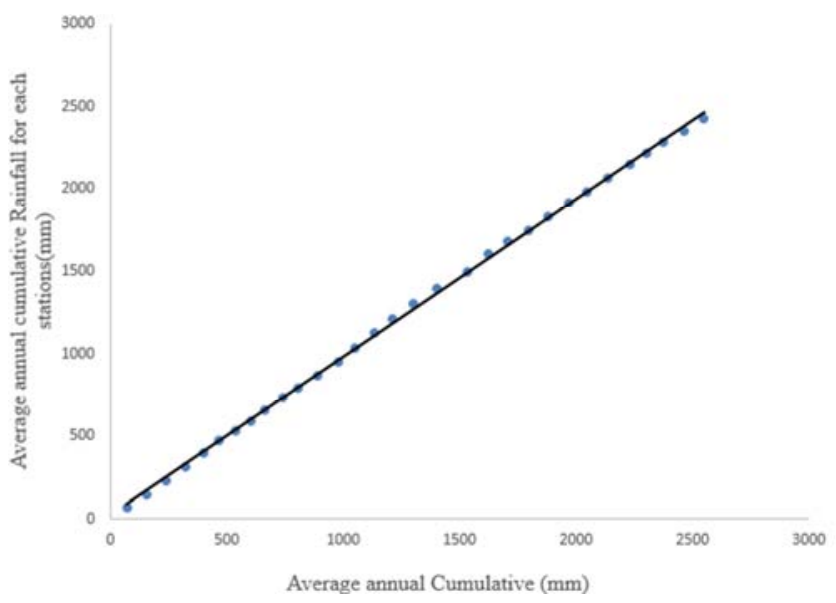

Figure 4. Double mass curves for four representative meteorological station of Mojo.

\subsection{SWAT Model Input}

The SWAT model works with spatial and temporal data. Spatial data include elevation, soil type, slope and land use/cover. To delineate the watershed Digital Elevation Model (DEM) grid, digitized stream network files were loaded using the watershed delineation tool. Land use and land cover was also one of the most important spatial input data in SWAT Model. The land use/cover data was 
reclassified according to requirement of the SWAT model. Soil data are another spatial input required by SWAT model. SWAT model requires different soil textural and physicochemical properties such as soil texture, available water content, hydraulic conductivity, bulk density and organic carbon content for different layers of each soil type. Basic physical and chemical property of major soil types in watershed were collected from the Ministry of Water and Electricity (MOWIE).

The temporal input data for the model are meteorological datasets and stream flow data. For this study, the meteorological data element such as daily precipitation, minimum and maximum air temperature, Relative humidity, wind speed and sunshine hours for thirty one years (19872017) of four representatives' weather station were obtained from national meteorological agency. Station those have missing meteorological data values were filled using weather generator model (WXGEN). Other parameters required in User weather generator were calculated using pcpSTAT.exe and dew02.exe computer program. PcpSTAT.exe is a computer program used to calculate statistical parameters of daily parameters of daily precipitation data used by weather generator of the SWAT model and the other weather parameters such as average daily dew-point temperature and humidity was calculated using dew02.exe computer program.

Stream flows are another temporal input data required by SWAT model for calibration and validation. For calibration purpose, Arc SWAT requires stream flow data as an input. Stream flow data of the Mojo sub-basin is collected from Ministry of Water, Irrigation and Electricity and is used for calibration and validation of the model. The daily discharge of hydrological gaging station of the Mojo sub-basin for about 30 years continues data (1987-2016) where used for performing sensitivity analysis, calibration (1987-2001) and validation (2002-2016) of the model.

\subsection{SWAT Model Setup}

\subsubsection{Watershed Delineation}

The first step in creating SWAT model input was delineation of watershed from a DEM. Inputs entered into the SWAT model were organized to have spatial characteristics. The SWAT model provides three spatial levels: the watershed, the sub basins, and the hydrologic response units (HRUs). Each level characterized by a parameter set and input data. The largest spatial level, the watershed, refers to the entire area being represented by the model. The watershed and sub watershed delineation was done using DEM data. The watershed delineation process includes five major steps, stream definition, outlet and inlet definition, Watershed outlet selection and definition and calculation of sub basin parameters. For the stream definition the threshold based stream definition option was define the minimum size of the sub basin. The Arc SWAT interface allows the user to fix the number of sub basin by deciding the initial threshold area which was used to obtain detail watershed sub-basin. The SWAT model development for particular area was defining watershed boundary. These boundaries normally fall along the ridges in a watershed. [6] and [16] indicated that GIS data resolution has significant impact on model output uncertainty. So, in order to minimize model uncertainty associated with input data Mojo watersheds covering a total drainage area of $2017.09 \mathrm{~km}^{2}$ is delineated and subdivided into 25 sub-basins based on the minimum threshold area of 5000 ha [8]). Because, the SWAT model with greater resolution of soil property and a greater number of HRUs produce the best calibration statistics [18]. Accordingly, multiple HRUs were defined based on the minimum threshold level that accounts for $10 \%$ Land use, $15 \%$ soil and $10 \%$ slope threshold combination to have a better estimation of stream flow of Mojo watershed. As Figure 7 shows delineated Mojo Watershed and sub-basin from Awash basin with the geographic location of the meteorology and river gauging station.

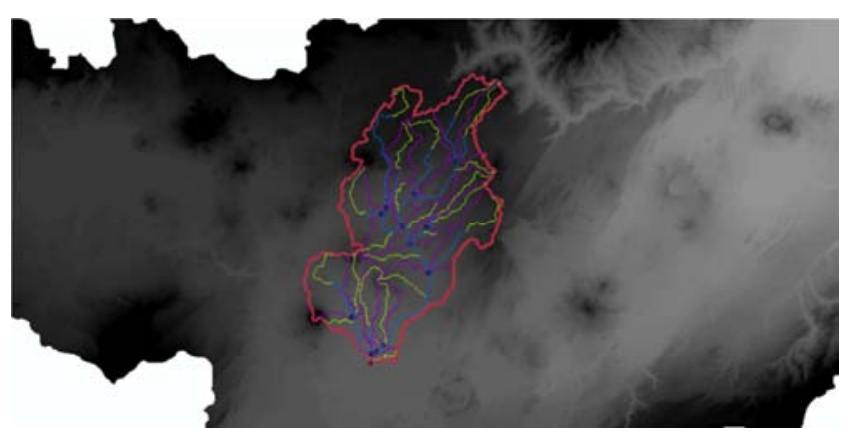

Figure 5. Delineated Mojo Watershed from Awash Basin DEM.

\subsubsection{Hydrological Response Unit}

After watershed delineation, sub-basin was subdivided into areas having unique land use, soil and slope so called hydrologic response units (HRUs). The HRU Analysis tool in Arc SWAT helped to load land use, soil layers and slope map to the project. HRU analysis in SWAT includes divisions of HRUs by slope classes in addition to land use and soils by considering multiple slope option. The spatial inputs like LULC, soil and slope map was reclassified in order to correspond with the parameters in the SWAT database. After reclassifying the land use, soil and slope in SWAT database, all these physical properties were made to be overlaid for HRU definition. Different researchers set default threshold level in SWAT for land cover, soil and topography depend on project goal and detail required by the modeler $[22,24]$ recommend the default threshold level as 5\%,20\% and $10 \%$ for land, soil and slope respectively. For this study, the threshold levels were set to $10 \%$ for land use, $15 \%$ for soil and $10 \%$ for slope. The land use threshold level is used to eliminate minor land uses in each sub-basin and covered land use area below the threshold is eliminated. The remaining area after elimination process is reapportioned so that $99.9 \%$ of the land area in the sub-basin is modeled. The same is true for soil classes and slope ranges distribution in all sub-basins.

\subsubsection{Sensitivity Analysis}

The determination of the most sensitive parameters was the key and first step, for model calibration and validation at the watershed scale. Sensitivity analysis was the process of 
identifying the model parameters that exert the highest influence on model calibration or on model predictions. Sensitivity analysis was done using SWAT CUP which is a computer program for calibration of SWAT models using a SUFI2 global sensitivity method, for the whole catchment area as applied by [24]. These parameters were selected from previous studies done in Mojo watershed [24]. Sensitive parameters were selected based on the calculated value of $t-$ stat and P-value in SWAT_CUP software. In this analysis, the larger in absolute value of $t$-stat and the smaller the $p$-value, considered and most sensitive the parameter. Accordingly, the sensitivity analysis was made for selected parameters (Table 1) to rank their potential influence based on t-stat and P-value. The analysis was made with observed flow data measured at Mojo station found near the outlet of the subbasin delineated.

In the process of parameter identification an important consideration for applying parameter identifiers is that the changes made to the parameters should have physical meanings and should reflect physical factors such as soil, Land use, elevation, etc. [1]. Therefore the following notation where used; X_Code to indicate the type of change to be applied to the parameter, V_means the existing parameter value is to be replaced by the given value, a means the given value is added to the existing parameter value, and $\mathrm{r}$-means the existing parameter value is multiplied by $(1+\mathrm{a}$ given value). The presented encoding scheme allows us to make distributed parameters dependent on important influential factors depending on the nature of the parameter.

\subsection{Calibration and Validation of SWAT Model}

Model calibration and validation are necessary and critical steps in any model application. Automatic calibration and uncertainty analysis incorporated in SWAT 12 via the SWATCUP (SWAT Calibration and Uncertainty Procedures) software developed and tested by [1] with the semiautomated program SUFI2 (Sequential Uncertainty Fitting ver. 2) was used for this study. SUFI-2 is widely used (example $[23,4,8]$ mainly due to the relatively fewer required number of runs to reach an acceptable calibration results. Additionally, [23] concluded that SUFI-2 requires 230 times fewer runs than the other programs of the SWATCUP. Therefore, based on these two reasons SUFI-2 was selected for calibration and validation of the SWAT models.

The relevant model parameter selected based on their sensitivity, t-stat and p-value, were Calibrated on monthly bases for stream flow using SWAT-CUP, SUFI2 interface by changing the parameter value within the range until the predicted value was reasonably in line with that of observed value and its accuracy was evaluated with Nash-Sutcliffe coefficient (NSE) and Coefficient of determination $\left(\mathrm{R}^{2}\right)$.

The stream flow data of the period (1987-2016) having continuous data was used for calibration and validation of the model. The data of (1987-2001) for calibration and (20022016) year data were used for validation. So, based on sensitivity analysis ranks the top thirteen relevant model parameters selected were used as starting points for model calibration on monthly bases for the stream flow. Then, calibration of the model was done by changing the parameter value within the range until the simulated value is reasonably fit with that of observed value. After the model is calibrated, the accuracy of the model was evaluated during the validation process with the help of the data (2002-2016), which are not used during the calibration process without any adjustment to the calibrated value.

\subsection{Model Performance Evaluation}

The accuracy of SWAT simulation results was determined by examination of the coefficient of determination $\left(R^{2}\right)$, the Nash and Sutcliffe (1970) model efficiency coefficient (NSE), the root mean square error (RMSE), percentage bias (PBAIS) and observation standard deviation ratio (RSR).

\subsubsection{Coefficient of Determination}

The $\mathrm{R}^{2}$ value is an indicator of the strength of the linear relationship between the observed and simulated values, while the (NSE) simulation coefficient indicates how well the plot of observed versus simulated values fits the 1:1 line. It measures how well the simulated versus observed regression line approaches an ideal match and ranges from 0 to 1 , with a value of 0 indicating no correlation. The $\mathrm{R}^{2}$ statistic is calculated as:

$$
R^{2}=\left[\frac{\sum_{i=1}^{n}\left(O_{i}-O_{a v r}\right)\left(P_{i}-P_{a v r}\right)}{\sum_{i=1}^{n}\left(O_{i}-O_{a v v}\right)^{2} \sum_{i=1}^{n}\left(P_{i}-P_{a v r}\right)^{2}}\right]^{2}
$$

Where $\mathrm{R}^{2}=$ Coefficient of determination, $\mathrm{n}$ is the total number of observation $\mathrm{O}_{\text {avr }}$, Pavr, are mean observed and predicted value respectively, $\mathrm{Oi}=\mathrm{Observed}$ (measured) value and $\mathrm{Pi}=$ Modelled (predicted) value.

\subsubsection{Nash-Sutcliffe Efficiency (NSE)}

The Nash-Sutcliffe efficiency (NSE) indicates how well the plot of observed versus simulated data fits the 1:1 line. It generally ranges from $-\infty$ to 1 . Higher value of NSE indicates better accuracy of model prediction whereas lower NSE indicates poor model prediction. If the NSE is between 0 and 1 , it indicates deviations between measured and simulated values. If ENS is negative, predictions are very poor, and the average value of output is a better estimate than the model prediction (Nash and Sutcliffe, 1970). In general, model simulation can be judged as satisfactory if NSE $>0.50$, Moriasi et al. (2007). NSE is computed as shown below:

$$
E_{N S}=\frac{\left[\sum_{i=1}^{n}\left(Q_{s i m}-Q_{o b s}\right)\right]^{2}}{\left[\sum_{i=1}^{n}\left(Q_{o b s}-Q_{o b s, m}\right)\right]^{2}}
$$

Where: $Q_{\text {obs }}$ is observed flow $\left(\mathrm{m}^{3} / \mathrm{s}\right), \mathrm{Q}_{\text {sim }}$ is the simulated flow $\left(\mathrm{m}^{3} / \mathrm{s}\right), Q_{\text {obs, } m}$ is the observed measured flow $\left(\mathrm{m}^{3} / \mathrm{s}\right)$ and $\mathrm{Q}_{\text {sim, } \mathrm{m}}$ is average simulated flow $\left(\mathrm{m}^{3} / \mathrm{s}\right)$. 


\subsubsection{Percent Bias (PBIAS)}

Percent bias measures the average tendency of the simulated data to be larger or smaller than their observed counterparts. The optimal value of PBIAS is 0.0 , with low magnitude values indicating accurate model simulation. Positive values indicate model underestimation bias, and negative values indicate model overestimation bias [9] as cited in [[13]. PBIAS is computed as shown below.

$$
\text { PBIAS }=\frac{\sum_{i=1}^{n}\left(O_{i}-S_{i}\right)}{\sum_{i=1}^{n}(O i)} * 100
$$

Where, PBIAS is the deviation of data being evaluated, expressed as a percentage. If PBIAS $\pm 25 \%$ for stream flow and PBIAS $\pm 55 \%$ for sediment, the model simulation can be judged as satisfactory.

\subsubsection{Root Mean Square error Observation Standard Deviation Ratio (RSR)}

RSR incorporates the benefits of error index statistics and includes a scaling/normalization factor, so that the resulting statistic and reported values can apply to various constituents. RSR varies from the optimal value of " 0 ", which indicate zero root mean square error (RMSE) or residual variation and therefore Perfect model simulation, to a large positive value. Generally, if the value of RSR $\leq 0.70$ the model simulation can be considered as satisfactory [13].

$$
\mathrm{RSR}=\frac{\mathrm{RMSE}}{\text { STDEVobs }}=\frac{\sqrt{\sum_{\mathrm{i}=1}^{\mathrm{N}}(\mathrm{Oi}-\mathrm{Si})^{2}}}{\sqrt{\sum_{\mathrm{i}=1}^{\mathrm{n}}(\mathrm{Oi}-\mathrm{Savr})^{2}}}
$$

\begin{tabular}{|c|c|c|c|c|}
\hline Performance Rating & RSR & NSE & $\mathbf{R}^{2}$ & $\mathbf{P}_{\text {BIAS }}$ \\
\hline V. good & $0.00 \leq \mathrm{RSR} \leq 0.50$ & $0.75 \leq \mathrm{NSE} \leq 1.00$ & $0.75<\mathrm{R}^{2} \leq 1.00$ & $\mathrm{P}_{\mathrm{BIAS}} \leq \pm 10$ \\
\hline Good & $0.50 \leq \mathrm{RSR} \leq 0.60$ & $0.65<\mathrm{NSE} \leq 0.75$ & $0.6<\mathrm{R}^{2} \leq 0.75$ & $\pm 10 \leq \overline{\mathrm{P}}_{\mathrm{BIAS}} \leq \pm 15$ \\
\hline Satisfactory & $0.60 \leq \mathrm{RSR} \leq 0.70$ & $0.50<\mathrm{NSE} \leq 0.65$ & $0.5<\mathrm{R}^{2} \leq 0.6$ & $\pm \leq \mathrm{P}_{\mathrm{BIAS} \leq \pm 25}$ \\
\hline Unsatisfactory & $\mathrm{RSR}>0.7$ & $\mathrm{NSE} \leq 0.50$ & $\mathrm{R}^{2} \leq 0.25$ & $P_{\text {BIAS } \geq \pm 25}$ \\
\hline
\end{tabular}

Table 2. Classification of statistical indices (Moriasi et al., 2007).

\subsubsection{P-Factor and r-Factor}

The above statistical indices only apply to the comparison of two signals and are not adequate when outputs are expressed as uncertainty bands. In this case, as the simulation results are usually expressed by the $95 \%$ prediction uncertainties (95PPU), they cannot be compared with the observation signals using the traditional $\mathrm{R}^{2}$ and NSE statistics. For this reason, [3, 4] suggest using two measures, referred to as the $\mathrm{p}$-factor and the $\mathrm{r}$-factor. The $\mathrm{p}$-factor is the percentage of the measured data bracketed by the 95PPU. This index provides a measure of the model's ability to capture uncertainties. As all the "true" processes are reflected in the measurements, the degree to which the 95PPU does not bracket the measured data indicates the prediction error. Ideally, the p-factor should have a value of 1 , indicating $100 \%$ bracketing of the measured data, hence capturing or accounting for all the correct processes. The r-factor, on the other hand, is a measure of the quality of the calibration and indicates the thickness of the95PPU. Its value should ideally be near zero, hence coinciding with the measured data. The combination of $\mathrm{p}$-factor and $\mathrm{r}$-factor together indicate the strength of the model calibration and uncertainty assessment, as these are intimately linked.

The detail explanations of SWAT model was described as follow.

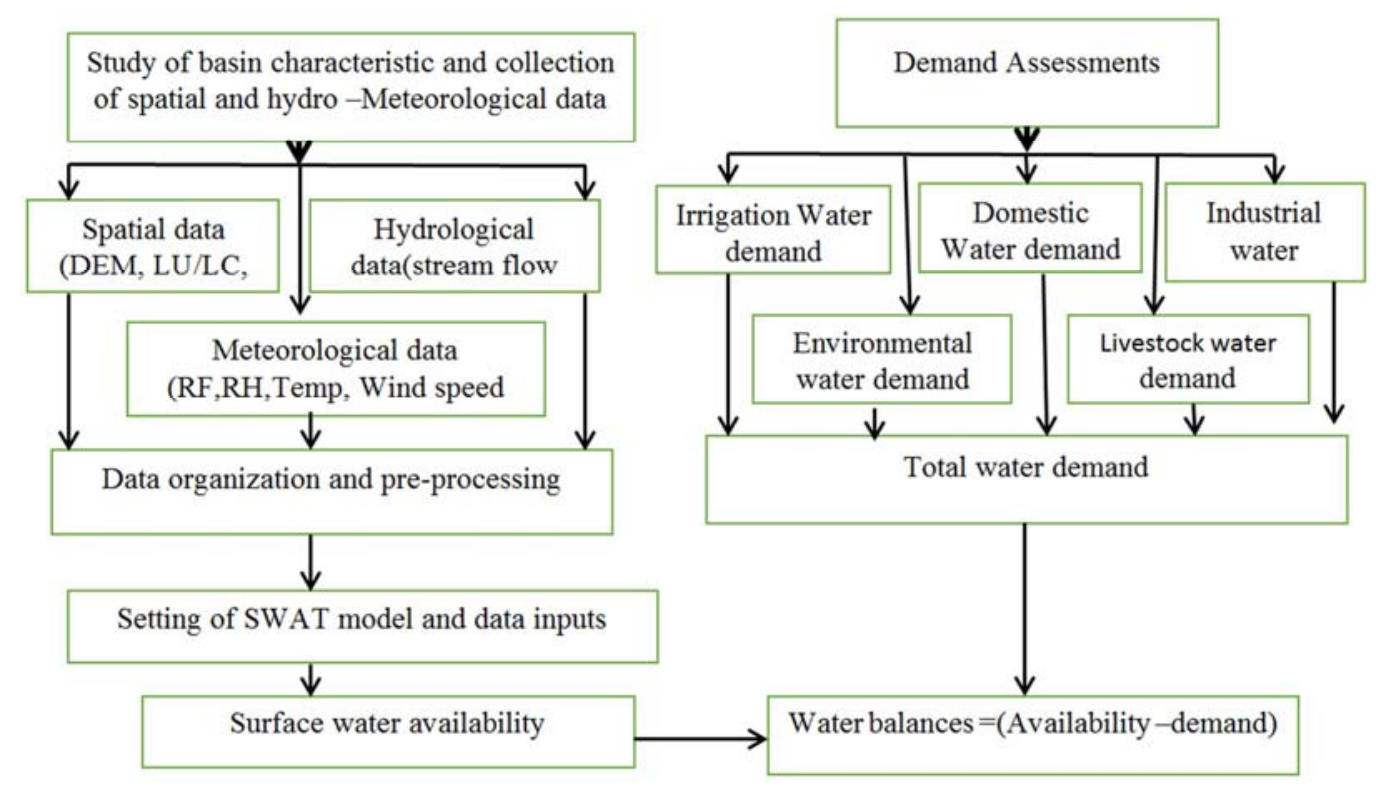

Figure 6. Conceptual frame work of Arc SWAT for stream flow simulation yield. 


\section{Results and Discussions}

Performance Evaluation of Hydrological Model.

\subsection{Sensitivity Parameters}

Sensitivity analysis was done using SWAT-CUP, global sensitivity analysis, as suggested by [12] to consider seasonal sensitivity of stream flow parameters for a catchment area. The range of variations for these parameters is based on a listing provided in the SWAT -CUP manual [15] and the previous studies. The number of sensitive parameters to be considered ranged between 2 and19 and depended on the complexity of the hydrological features in the catchments and modeling efforts [14]. Accordingly, among the selected parameter for sensitivity analysis, the top thirteen ranking parameters, based on the highest absolute value of t-stat and low p-value, were selected as starting points for model calibration in table 3 .

The most sensitive parameters during the model calibration step was presented at the top of the ranking as shown in figure 9 below that was the highest value of $t$ - stat index module which represent the ratio of parameter coefficient by the standard error; and the lower value of the" $p$ value" which was related to the rejection of hypothesis that addition in the value parameter provides a significant increase in the variable response [4]. In this study, the parameters towards evaporation like (EPCO and ESCO), surface runoff (CANMX) and ground water parameters like (GW_DELAY, ALPHA_BF, and GWQMN) are very low. The parameters involving surface runoff $(\mathrm{CN} 2)$ and ground water (ALPHA BNK) were the most Sensitive parameter in flow simulation. On the other hand, according to the result from the global sensitivity analysis the curve number $\left(\mathrm{CN}_{2}\right)$, was found to be the most sensitive parameter followed by base flow alpha (ALPHA BNK) of ground water flow, effective hydraulic conductivity in main channel $\left(\mathrm{CH} \_\mathrm{K} 2\right)$, available water capacity of soil layer (SOL AWC), average slope steepness (HRU_SLP), surface runoff lag time (SURLAG), manning's “n” values for main channel $\left(\mathrm{CH}_{-} \mathrm{N}_{2}\right)$ and etc. as ranking from one up to thirteen position were selected for model calibration. Table 3 below shows the fitted value of thirteen most sensitive parameters for stream flow calibration \& validation.

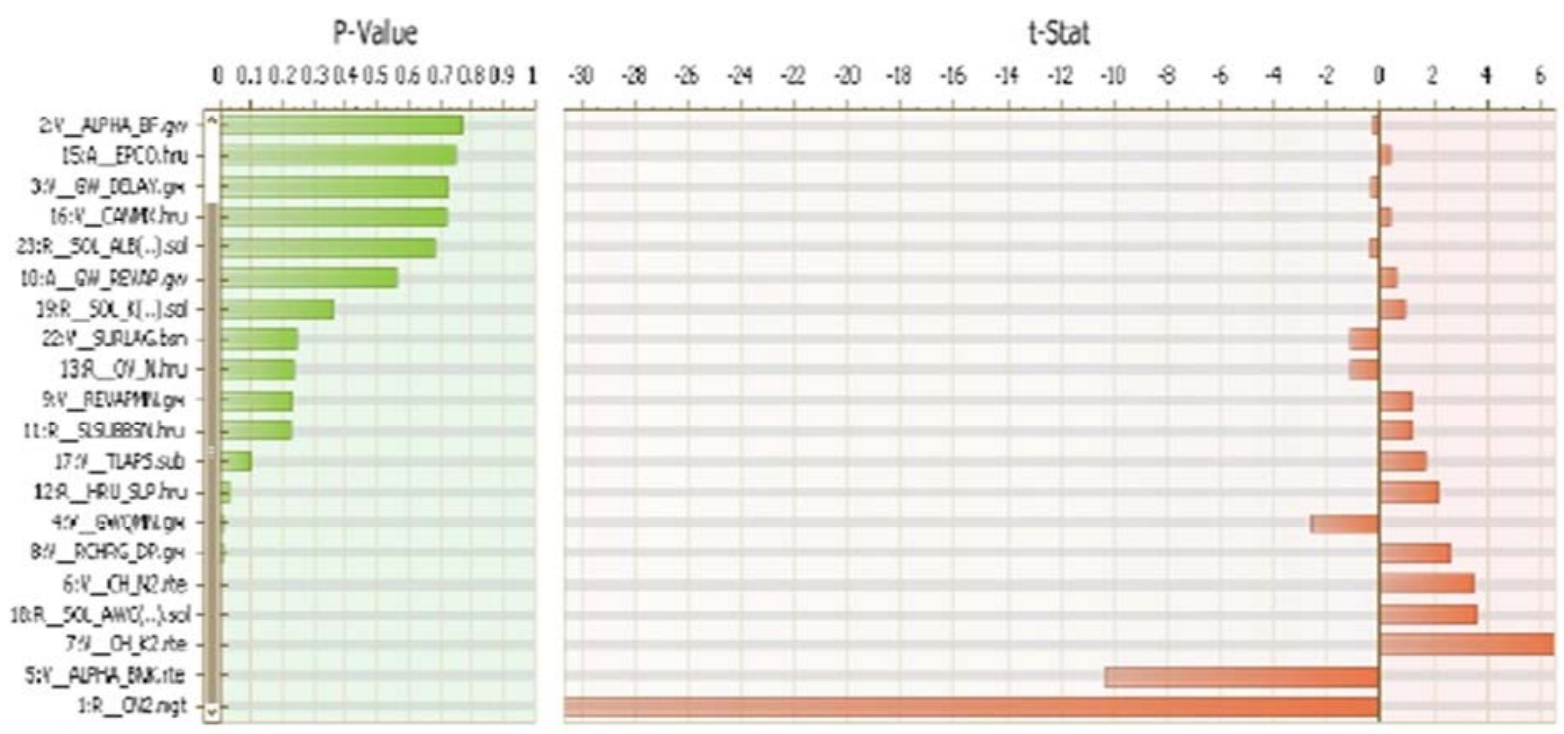

Figure 7. Screen shot of Global Sensitivity output of Stream flow sensitivity analysis during Calibration and Validation.

FLOW_OUT_25

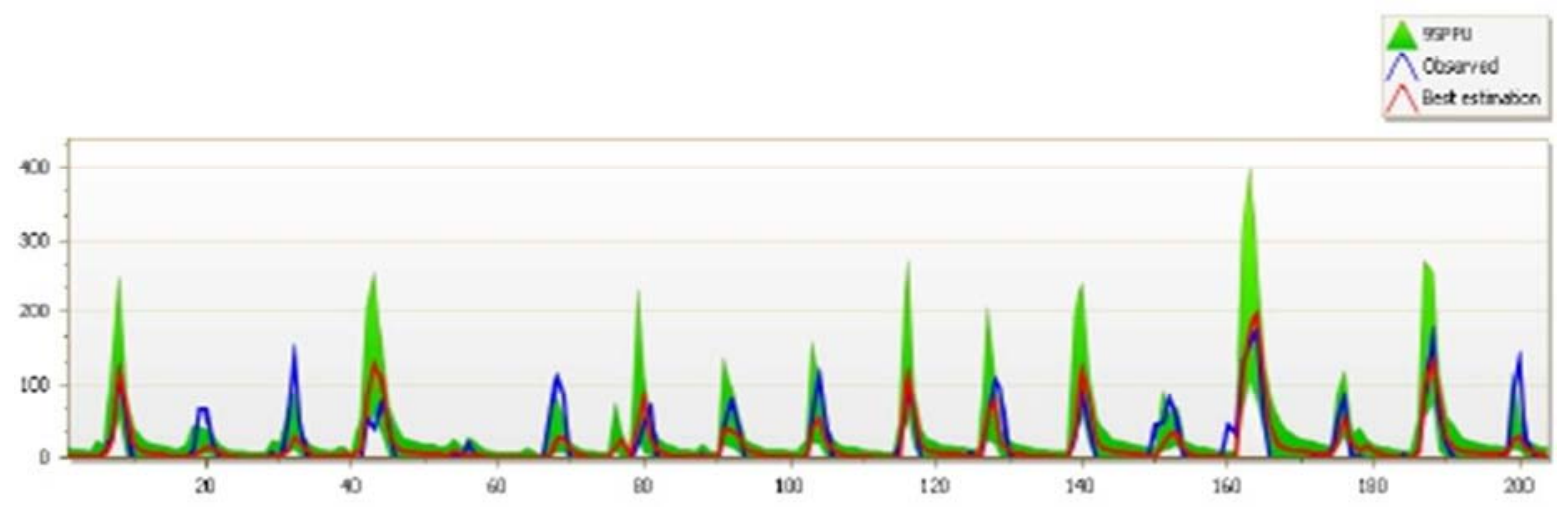

Figure 8. 95ppu plot by SUFI-2 during Sensitivity analysis for stream flow. 
Table 3. Summary of 13 most global sensitivity parameter ( $t$ - and $p-$-) analysis values.

\begin{tabular}{lllll}
\hline SN & Parameter Name & t - Stat & P-Value & Ranking \\
\hline 1 & r_OV_N & 0.0476673 & 0.962245 & 13 \\
2 & r_TLAPS & -0.141392 & 0.88835 & 12 \\
3 & r_SLSUBBSN & 0.50192 & 0.618783 & 11 \\
4 & r_REVAPMN & -0.923268 & 0.362015 & 10 \\
5 & v_TLAPS.sub & 1.0578358 & 0.29717716 & 9 \\
6 & r_HRU_SLP & 1.279305 & 0.2089742 & 8 \\
7 & a_GWQMN.gw & -1.385735 & 0.174352969 & 7 \\
8 & v_CHARG_DP & 1.579307046 & 0.1230133 & 6 \\
9 & v_CH_N & 1.781452 & 0.0832772 & 5 \\
10 & r_SOL_AWC & 1.784614 & 0.0827536 & 4 \\
11 & v_CH_K $_{2}$ & 2.1667255 & 0.0369523 & 3 \\
12 & v_ALPHA & -4.72602276 & 0.000034599 & 2 \\
13 & r_CN & 16.363445523 & 0.00 & 1 \\
\hline
\end{tabular}

The rank for each parameter was assigned depending on Pvalue and t-stat. Here, t-stat provides a measure of sensitivity and hence larger in absolute values are more sensitive. On the other hand, P-value indicates the significance of the sensitivity and hence a value close to zero has more significance. Therefore, ranking in both cases (t-stat or Pvalue) give the same result i.e. a parameter will have the same rank whether it is ranked based on the t-stat or $\mathrm{P}$ value. Table 3 above shows the performance evaluation of most parameters depending on the $\mathrm{p}$-values and t- values.

\subsection{SWAT Model Calibration and Validation}

Some of the causes of uncertainty occurrences are due to the changes of land use land cover, changes of forest land into urban area, release of waste water in to the watershed, climatic data like Rainfall and Temperatures as well as unreliable recorded Observed data. Given the above possible errors, calibration and validation results of the Mojo watershed can be qualified as "Good to very Good" for stream flow yield in this study after calibration and validation. This may be due to a good quality of the input data as well as small conceptual model errors in the dominant processes in the watershed. During calibration process to maximize the model efficiency hydrological parameters selected during sensitivity analysis using SUFI2 algorithm were considered. In other way, the models approximate the reality of the natural systems. Both graphical methods and statistical tests are used in model calibration and validation. The details simulation of the basin was given in Table 4 .

Table 4. Details of Model Simulation for the Mojo Basin.

\begin{tabular}{lll}
\hline SI. No & Simulation details & Remark \\
\hline 1 & Simulation length & 31 years \\
2 & Warm up period & 3 year \\
3 & Calibration Period & 15 Years excluding warm up period \\
4 & Validation period & 15 Years \\
5 & Total number of sub basin & 25 \\
\hline
\end{tabular}

\begin{tabular}{lll}
\hline SI. No & Simulation details & Remark \\
\hline 6 & Total numbers of HRU & 42 \\
7 & Input metrological data & Measured \\
8 & total basin area & $2017.09 \mathrm{~km}^{2}$ \\
\hline
\end{tabular}

The calibration was performed using monthly observed data from the year 1987 to 2001excluding the warm up periods. The Calibrated model was validated using data from 2002 to 2016 on monthly time step. Both the calibration and validation were taken for equal periods of fifteen years.

\subsection{Model Calibration}

After sensitive parameters identified the model were calibrated and validated using the hydrological parameters selected during sensitivity analysis. The calibration process using SUFI-2 algorithm gave the final fitted value of the most sensitive parameters for the watershed (Table 5).

Table 5. Final calibrated sensitive parameters.

\begin{tabular}{llll}
\hline Parameter Name & Min.value & Max_value & Fitted Value \\
\hline r_CN2.mgt & -0.2 & 0.2 & -0.021542 \\
r__ALPHA_BNK.rte & 0.0 & 1.0 & 0.039968 \\
r_RCHRG_DP.gw & 0.0 & 0.2 & 0.090479 \\
r_CH_K2.rte & 0.0 & 150.0 & 1.736827 \\
r_CH_N2.rte & 0.0 & 0.5 & 0.483162 \\
r_TLAPS.sub & -10.0 & 10.0 & -4.996675 \\
r_HRU_SLP.hru & 0.0 & 0.2 & 0.001056 \\
r_REVAPMN.gw & 0.0 & 10.0 & 5.79177 \\
r_SURLAG.bsn & 0.0 & 10.0 & 7.31308 \\
r_SOL_AWC (...).sol & -0.2 & 0.4 & 0.026561 \\
r_SOL_K (...).sol & -0.5 & 0.5 & -0.225174 \\
r_GW_REVAP.gw & -0.1 & 0.0 & -0.032535 \\
r_OV_N.hru & -0.2 & 0.0 & 0.034993 \\
\hline
\end{tabular}

From the 23 parameters for the stream flow analyzed the most 13 parameters had been selected based on the performance evaluation criteria. So it shows the most sensitive parameters that were selected during both calibration and validation period without any changes of parameters. Initially, the decreasing curve number at moisture condition II $\left(\mathrm{CN}_{2}\right)$, and GW_REVAP increasing were over prediction during calibration or first iteration. Setting only CN2 to their Calibrated values improved efficiency of SWAT. CN2 is found to be a most important parameter in calibration of SWAT [6]; Noor et al., 2014; Ridwansyah et al. 2014; and Kumar et al., 2014) as cited by [24] and contributes directly to surface runoff generation. On this study, model under prediction were adjusted by increasing REVAPMN and SOL_AWC. All above parameters values were adjusted manually for calibration. The performance of the model was evaluated using $\mathrm{R}^{2}, \mathrm{E}_{\mathrm{NS}}$ and $\mathrm{P}_{\mathrm{BIAS}}$ statistical measures for both manual and autocalibration. Evaluations were performed at monthly time scales and the result of statistical parameters during calibration obtained were 0.80 for $\mathrm{R}^{2}, 0.75$ for $\mathrm{E}_{\mathrm{NS}}$ and -10.6 
for $\mathrm{P}_{\mathrm{BIAS}}$. The values indicate that there is good agreement between observed and simulated stream flow of Mojo watershed. Figure 10 below shows hydrography comparison during model calibration.

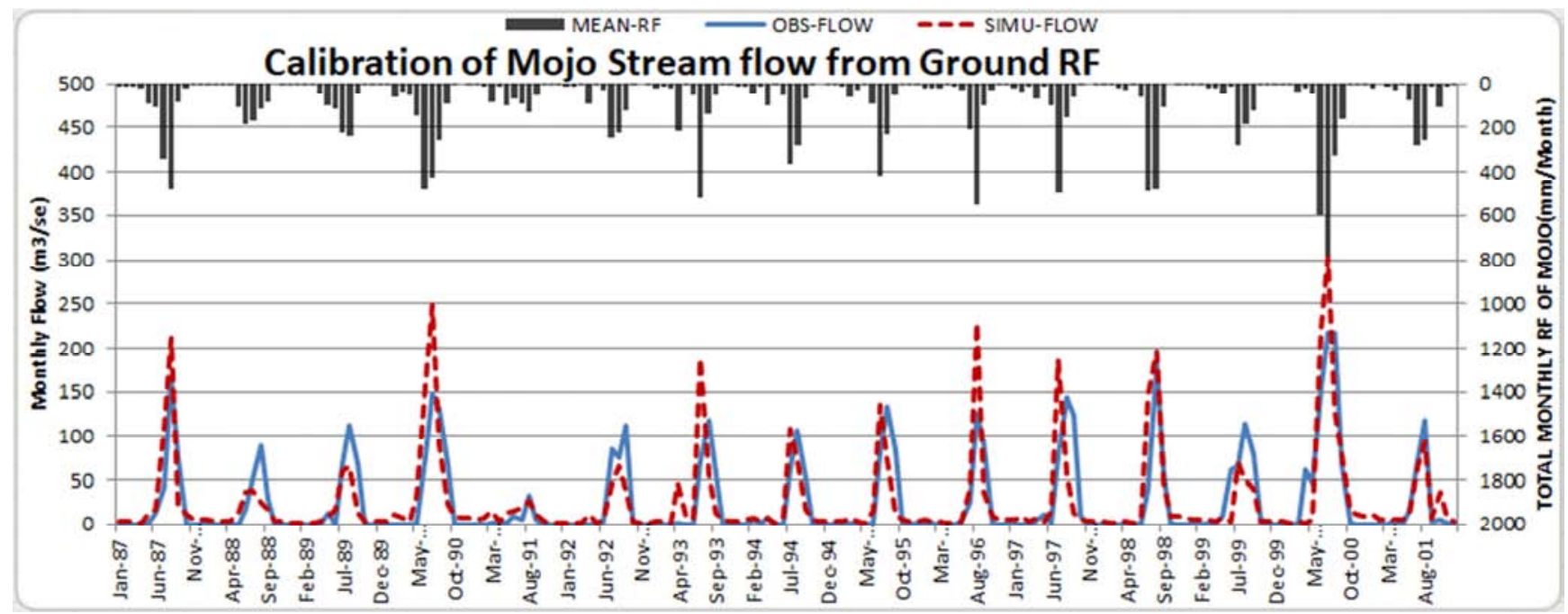

Figure 9. Calibration of Observed \& Simulated stream flow of Mojo Watershed.

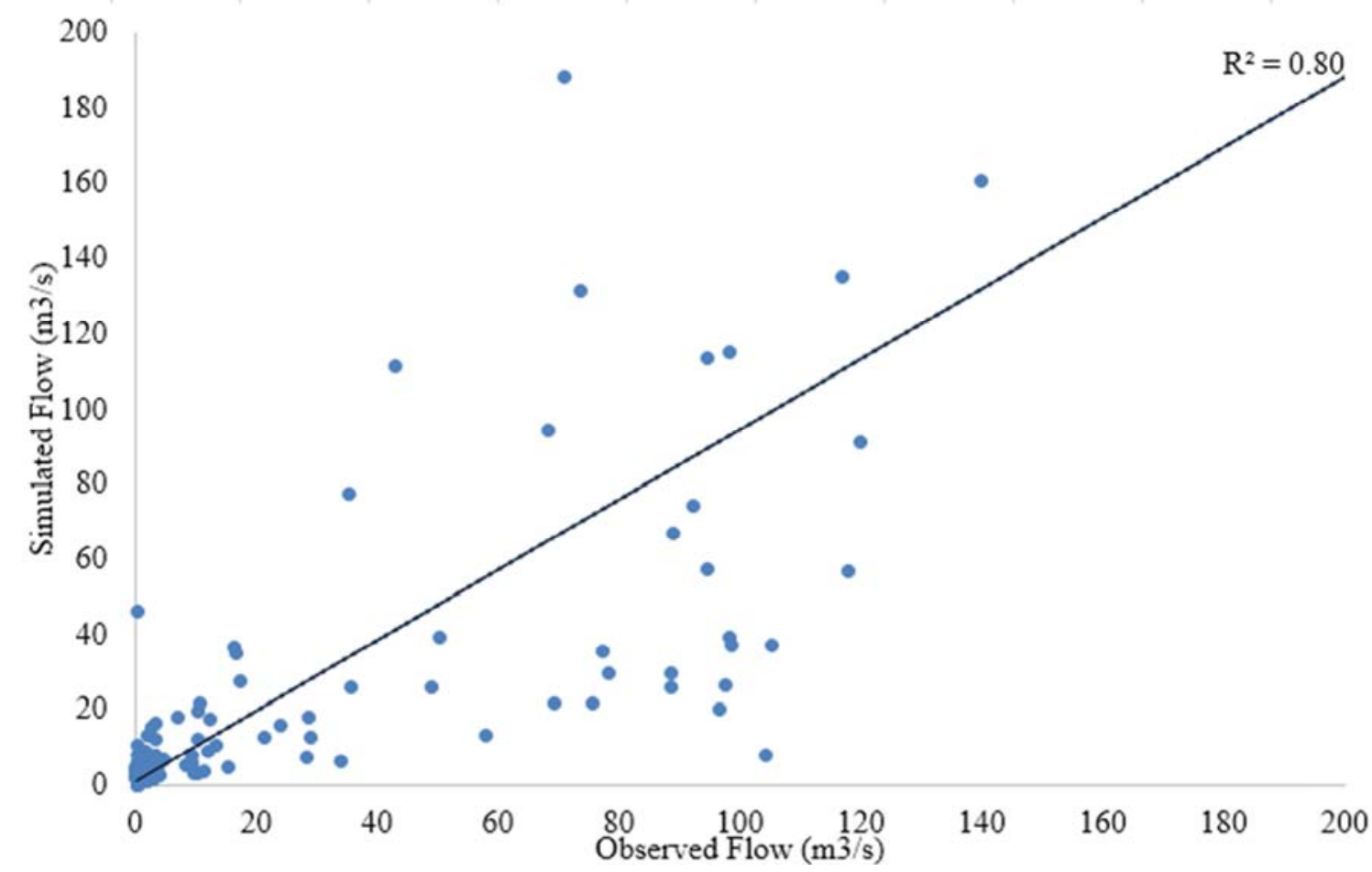

Figure 10. Scatter plot of Observed and Simulated flow of the Calibration period.

\subsection{Model Validation}

Validation of model results was necessary to increase user confidence in model predicting capability. Fifteen year monthly observed data (2002-2016) were used for model validation without any adjustment of fitted value during calibration period. So the values of 0.76 for $\mathrm{R}^{2}, 0.69$ of $\mathrm{E}_{\mathrm{NS}}$ and $-14.4 \%$ of $\mathrm{P}_{\mathrm{BIAS}}$ were obtained. However, the result obtained during calibration and validation period in above is almost similar with the results of [13]. And but different from the result obtained by Lemma (2015) from Kulekhani watershed (153.54 ha) and Hassen et al. (2014) from May bar experimental watershed (113.75 ha) as cited by [24]. Here the results obtained confirm that SWAT model is more appropriate to be used for large watershed. Calibrated and validated model predictive performances values for Mojo River on monthly flows base are summarized in Table 6 and the time series plot of measured and simulated monthly flow for validation are shown in Figure 11 and Figure 12 below respectively. 


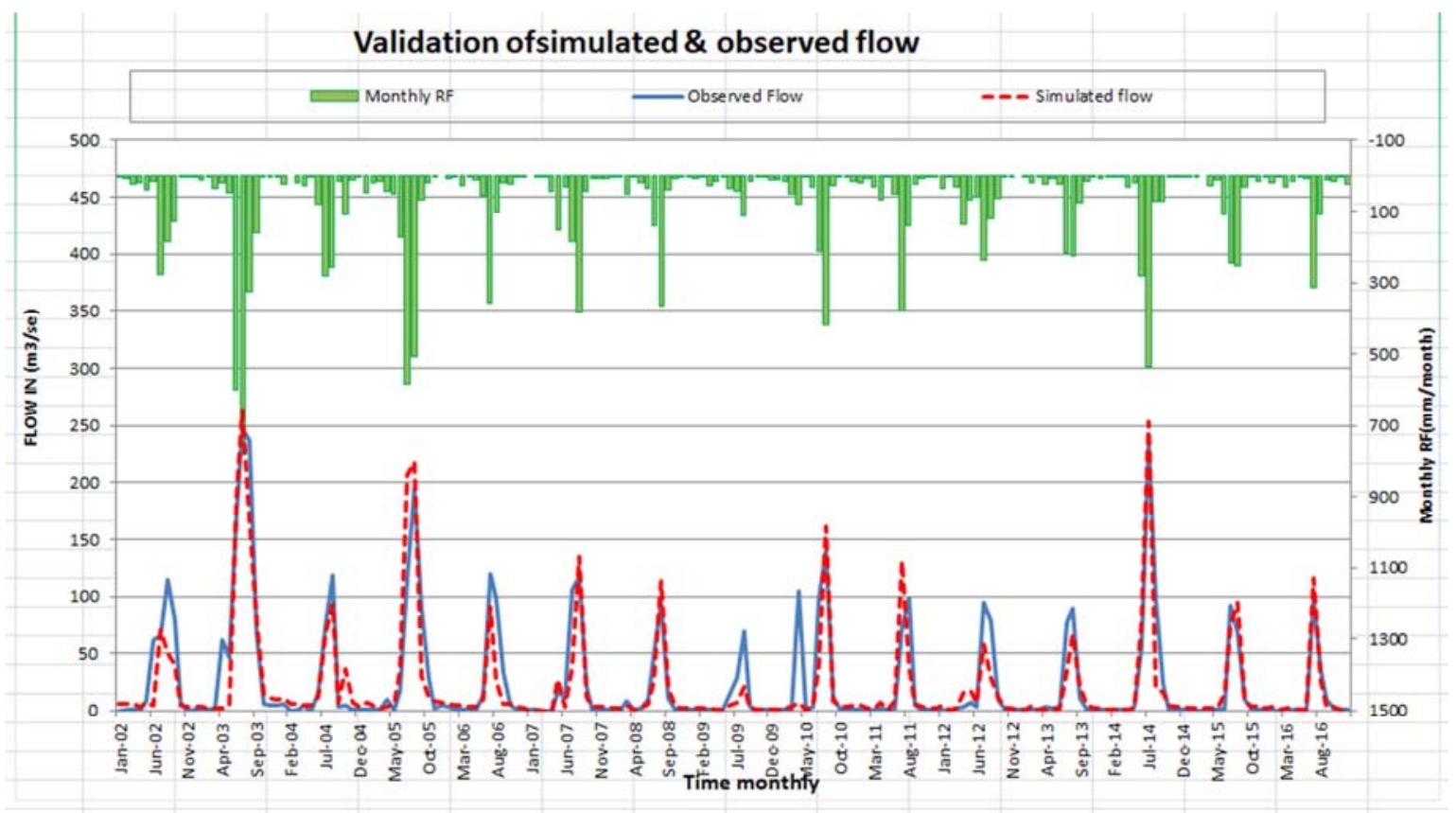

Figure 11. Validation of simulated \& observed stream flow of Mojo watershed.

Table 6. Model Performance indicator during Calibration and Validation.

\begin{tabular}{|c|c|c|c|c|c|c|c|}
\hline \multirow{2}{*}{ Period } & \multicolumn{7}{|c|}{ Model statistical efficiency measures } \\
\hline & $\mathbf{R}^{2}$ & NSE & ${ }_{b} \mathbf{R}^{2}$ & PBIAS & RSR & P-factor & r-factor \\
\hline Calibration & 0.80 & 0.75 & 0.78 & -10.6 & 0.5 & 0.82 & 0.01 \\
\hline Validation & 0.76 & 0.69 & 0.74 & -14.4 & 0.56 & 0.77 & 0.01 \\
\hline
\end{tabular}

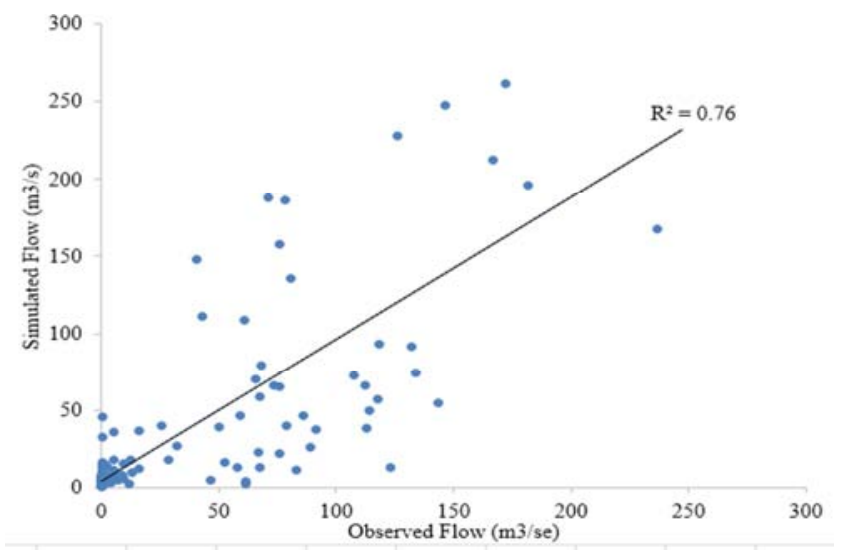

Figure 12. Scatter plot of observed and simulated flow for Validation period.

As it could been seen from table 6 the model under estimated stream flow compared to observed mean monthly stream flow in 1987, 1990, 1993, 1996, 1997 \& 2000 during calibration and 2003, 2005, 2007, 2010, $2011 \& 2014$ during validation period. One of the factors that have contributed to uncertainty of the model might be the effect of SWAT parameters that are considered to have negligible influence on the stream flow but cumulative of which would have affected the model performances. There were also unconsidered factors in modeling process that resulted in the model error is also another factors. Another source of uncertainty may be stream flow recorded at the gauge stations and uncertainty that rises from filling the missing flow data. In other way, the result of SUFI-2 indicates that the p-factor, percentages of data being bracketed by 95PPU, for the calibration period was 0.82 and 0.77 for the validation period. This was indicates that $82 \%$ and $77 \%$ of the measured data for calibration and validation respectively were correct simulated flow by the model while the remaining occur due to an errors of input data such as rainfall and temperature.

\section{Conclusions}

The Main aim of this study was to examine the water availability of mojo watershed using SWAT model for simulating stream flow. The model was successfully Calibrated and validated for the Mojo watershed using SWATCUP, SUFI-2 algorithms. In the process of model calibration the identified sensitive parameters helps to reduce the number of model parameters to thirteen. The selected parameters gave good results in minimizing the differences between observed and simulated stream flow yield. The model evaluation statistics for prediction of stream flow yield gave good to very good results that were verified by NSE greater than 0.69 and $\mathrm{R}^{2}$ greater than 0.75 . The Uncertainty related to the model and data used for stream flow was minimized by adjusting the value of selected parameters and the performance of the model $\mathrm{R}^{2}=0.80, \mathrm{NSE}=0.75$, error index $(\mathrm{RSR}=0.5)$ and percent bias $(\mathrm{PBIAS}=-10.6)$ obtained during calibration and $\mathrm{R}^{2}$ value 0.76 , NSE value 0.69 , RSR value 0.56 and percent bias -14.4 obtained during validation justified the capability of the model in simulating runoff. The 
Calibrated and validated model used to determine water balance of the watershed. The estimated annual water balance component indicates that $27.8 \%$ and $13.15 \%$ of the annual precipitation lost by evapotranspiration and deep percolation respectively. Whereas Lateral contribution $28.55 \%$, surface runoff $62.15 \%$ and groundwater $33.5 \%$ contributed to the total yield of the watershed. The total surface water yield of the Mojo River is estimated to be $0.504 \mathrm{BCM} /$ year.

\section{References}

[1] Abbaspour KC (2012) SWAT-CUP SWAT calibration and uncertainty programs - a user manual.

[2] Abbaspour, K. C. 2015. SWAT-CUP: SWAT Calibration and Uncertainty Programs - A User Manual.

[3] Abbaspour, K. C., C. A. Johnson, and M. T. van Genuchten. 2004. Estimating Uncertain Flow and Transport Parameters Using a Sequential Uncertainty Fitting Procedure. Vadose Zone Journal, 3: 134-1352.

[4] Abbaspour, K. C., J. Yang, I. Maximov, R. Siber, K. Bogner, J. Mieleitner, J. Zobrist, R. Srinivasan. 2007. Modelling hydrology and water quality in the pre-alpine/alpine Thur watershed using SWAT. Journal of Hydrology, 333, ly.

[5] Adeba Dereje and M. L Kansal (2015). Assessment of water scarcity and its impacts on sustainable development in Awash basin, Ethiopia. Indian Institute of Technology Roorkee.

[6] Cotter, A. S., I. Chaubey, T. A. Costello, T. S. Soerens, and M. A. Nelson. 2003. Water quality model output uncertainty as affected by spatial resolution of input data. J. of the American Water Resources Association, 39 (4): 977-986.

[7] Feyereisen, G. W., T. C. Strickland, D. D. Bosch, and D. G. Sullivan. 2007. Evaluation of swat manual calibration and input parameter sensitivity in the little river watershed. Transactions of the ASABE, 50 (3): 843-855.

[8] Gong, Y., S. Zhenyao, L. Ruimin, W. Xiujuan and T. Chen. 2010. Effect of Watershed Subdivision on SWAT Modeling with Consideration of Parameter Uncertainty. J. Hydrol. Eng. 15: 1070-1074.

[9] Gupta HV, Shian S, Yapo PO (1999) Status of automatic calibration for hydrologic models Comparison with multilevel expert calibration. J Hydrol Eng 4: 135-143.

[10] Kassa. 2016. Evaluation of water supply and demand: The case of Shambu town, Western Oromia, Ethiopia.

[11] Misgana Kebede and J. W. Nicklow. 2004. Sensitivity and uncertainty analysis coupled with automatic calibration for a distributed watershed model. Journal of Hydrology, 306: 127 145 .
[12] Misgana, K. Muleta. 2012. Improving Model Performance Using Season-Based Evaluation. J. Hydrol. Eng., 17: 191-200.

[13] Moriasi, D. N., J. G. Arnold, M. W. Van Liew, R. L. Bingner, R. D. Harmel and T. L. Veith. 2007. Model Evaluation Guidelines for Systematic Quantification of Accuracy in Watershed Simulations. Transactions of the ASABE, 50 (3): 885-900.

[14] Ndomba, P. M. and B. Z. Birhanu. 2008. Problems and Prospects of SWAT ModelApplications in NILOTIC Catchments: A Review. Nile Basin Water Engineering Scientific Magazine, Vol. 1. F.

[15] Neitsch, S. L., J. G. Arnold, J. R. Kiniry and J. R Williams. 2011. Soil and Water Assessment Tool Theoretical Documentation. Version2009. USDA Agricultural Research Service and Texas A\&M Black land Research Center, Temple, TX.

[16] Santosh, G. T., Y. R. Kolladi and T. V. Surya. 2010. Influence of Scale on SWAT Model Calibration for Stream flow in a River Basin in the Humid Tropics. Water Resour Manage, 24: $4567-4578$

[17] Seleshi B (2006). Assessment of water resources and recommendation to improve water resources management, Ref Adaa Pilot Learning Site of the project Improving Productivity and Market Success of Ethiopian Farmers, Oromia, Ethiopia. Final Draft Report, 2006, (IWMI).

[18] Shrestha, N. K., P. C. Shakti, and P. Gurung 2011. Calibration and Validation of SWAT Model for Low Lying Watersheds: A Case Study on the Kliene Nete Watershed, Belgium. HYDRO Nepal journal: Issue $\mathrm{N}^{\circ}$. 6 .

[19] Tessema, S. M., 2011. Hydrological modeling as a tool for sustainable water resources management: a case study of the Awash River basin. TRITA LWR. LIC 2056, Sweden.

[20] Van Rooijen D, Taddese G (2005). Urban sanitation and waste water treatment in Addis Ababa in the Awash basin, Ethiopia $34^{\text {th }}$ WEDC international conference, Addis Ababa, Ethiopia, 2009. Water, Sanitation and Hygiene Sustainable Development and Multi-sectoral approach.

[21] WBG. Global Economic Prospects: A Fragile Recovery; World Bank: Washington, DC, USA, 2006.

[22] Winchell, M., Srinivasan, R., Di Luzio, M., Arnold, J. G., 2010. ArcSWAT Interface for SWAT 2009 \{User's Guide. Texas Agricultural Experiment Station and USDA Agricultural Research Service. Temple (Texas). Page 16.

[23] Yang J, Reichert P, Abbaspour KC, Xia J, Yang H. 2008. Comparing uncertainty analysis techniques for a SWAT application to the Chaohe Basin in China. J Hydrol 358: 1-23.

[24] Zelalem. B, 2016. Calibration and Validation of SWAT model using stream flow and sediment load for Mojo watershed, Ethiopia. 